\title{
Heart Surgery Waiting Time: Assessing the Effectiveness of an Action
}

\author{
Abbas Badakhshan ${ }^{1}$; Mohammad Arab ${ }^{1, *}$; Mahin Gholipour ${ }^{2}$; Naser Behnampour ${ }^{3}$; Saeid \\ Saleki ${ }^{4}$ \\ ${ }^{1}$ Department of Health Management and Economics, School of Public Health, Tehran University of Medical Sciences, Tehran, IR Iran \\ ${ }_{2}^{2}$ Gastroenterology and Hepatology Research Center, Golestan University of Medical Sciences, Gorgan, IR Iran \\ 3 Public Health Department, School of Health, Golestan University of Medical Sciences, Gorgan, IR Iran \\ ${ }_{4}$ Amir Al-momenin Hospital, School of Medicine, Golestan University of Medical Sciences, Gorgan, IR Iran \\ ${ }^{*}$ Corresponding Author: Mohammad Arab, Department of Health Management and Economics, School of Public Health, Tehran University of Medical Sciences, Tehran, IR Iran. Tel: \\ +98-2188989134, E-mail: arabmoha@tums.ac.ir
}

Received: October 29, 2014; Revised: February 26, 2015; Accepted: March 18, 2015

\begin{abstract}
Background: Waiting time is an index assessing patient satisfaction, managerial effectiveness and horizontal equity in providing health care. Although heart surgery centers establishment is attractive for politicians. They are always faced with the question of to what extent they solve patient's problems.

Objectives: The objective of this study was to evaluate factors influencing waiting time in patients of heart surgery centers, and to make recommendations for health-care policy-makers for reducing waiting time and increasing the quality of services from this perspective.

Patients and Methods: This cross-sectional study was performed in 2013. After searching articles on PubMed, Elsevier, Google Scholar, Ovid, Magiran, IranMedex, and SID, a list of several criteria, which relate to waiting time, was provided. Afterwards, the data on waiting time were collected by a researcher-structured checklist from 156 hospitalized patients. The data were analyzed by SPSS 16 . The Kolmogorov Smirnov and Shapiro tests were used for determination of normality. Due to the non-normal distribution, non-parametric tests, such as Kruskal-Wallis and Mann-Whitney were chosen for reporting significance. Parametric tests also used reporting medians.

Results: Among the studied variables, just economic status had a significant relation with waiting time $(\mathrm{P}=0.37)$. Fifty percent of participants had diabetes, whereas this estimate was $43.58 \%$ for high blood pressure. As the cause of delay, $28.2 \%$ of patients reported financial problems, $18.6 \%$ personal problem and $13.5 \%$ a delay in providing equipment by the hospital.

Conclusions: It seems the studied hospital should review its waiting time arrangements and detach them, as far as possible, from subjective and personal (specialists) decisions. On the other hand, ministries of health and insurance companies should consider more financial support. It is also recommend that hospitals should arrange preoperational psychiatric consultation for increasing patients' emotionally readiness.
\end{abstract}

Keywords: Cardiovascular Surgical Procedures; Patient Satisfaction; Coronary Artery Bypass

\section{Background}

Heart diseases, as the most common cause of death in Iran and worldwide, have always been considered by the public and healthcare policy makers. Consequently, increasing the number of heart surgery centers has become an indicator of healthcare extension. Almost all of healthcare managers place the expansion of heart centers at the top of their career priorities. This issue is usually supported by national politicians, e.g. members of parliament and city council, beyond the people's concern. Therefore, purchasing and launching highly developed technologies has become a touchstone to assess politician's capacities. It varies from an ordinary clinic to the most advanced open-heart surgery and imaging facilities, such as catheterization labs. Despite this progress, waiting time is regarded as an appropriate determinant in evaluating healthcare quality, heart surgery prognosis (1) and patient satisfaction $(2,3)$, and all research efforts have been centered around measuring clinics or emer- gency department's waiting time $(4,5)$. Therefore, doing a research about estimating heart surgery waiting time seemed necessary. In countries with general health insurance coverage, waiting time limits healthcare access and decreases inpatient payment. Consequently, they will have more sources for providing state surgical or hospital services. Of course, it can harm people's health and cause inadequate use of elective services. Besides that, according to Siciliani et al. (6), less than 10 days waiting time can reduce total costs and it is better that managers use other methods for rationing, instead of waiting time. Besides being an important factor influencing patient satisfaction, waiting time is a quality measure for outpatient services. Keijzers et al. (7) assumed that waiting time, staff motivation and patient education are more effective on patient satisfaction than specialized team provision. Several scholars believe the time assigned by physicians to patients' visit is more satisfying than wait-

Copyright ( 2015, Iranian Red Crescent Medical Journal. This is an open-access article distributed under the terms of the Creative Commons Attribution-NonCommercial 4.0 International License (http://creativecommons.org/licenses/by-nc/4.0/) which permits copy and redistribute the material just in noncommercial usages, provided the original work is properly cited. 
ing time for receiving services (8). Waiting time is an expression of hospital services accessibility and a measure for hospital performance.

Solans-Domenech et al. (9) mentioned about an increasing pressure for the implementation of an equitable and patient needs-based system to rationing surgery. They also assumed that national official data on waiting lists for Spain and Catalonia do not allow conclusive lessons to be learned, regarding the impact that the austerity measures are having on waiting times for patients.

There are several examples about restricting the role of waiting time. In 2003, 1.5 million people in Canada were confined in waiting lists for receiving care. The same has happened for 132 thousands and 785 thousands of people in Nederland and Great Britain, respectively. Accompanied by efforts for providing healthcare, prioritization of people in waiting lists can ensure the assignment of services to neediest ones. Currently, our information about the priority setting of heart surgery services is elementary. A small number of clinicians work on priority setting and, among them, fewer specialists engage with ranking of surgical heart services. Ontario practitioners' decision is an example of waiting time application in reducing the impact of resource constrains. They delayed service provision for those with less acute need. This deprivation is in contrast to American policy, which is based on low income or lack of insurance (10). Eisenberg (11) highlighted that sociological factors, such as age, gender, race and social level, influence waiting time average.

In 2005, the Cardio-start charity group conducted several heart surgeries in Golestan province, Iran. Afterwards, Golestan University of Medical Sciences, Golestan, Iran, decided to establish a heart center in Amir Al-momenin Hospital of Kordkooy district. The main goal was reducing referral of Golestan and adjoining provinces' patients to Tehran and other large cities. One of the most important reasons for the urgent establishment of this action was the long waiting list of patients in the aforementioned regions.

\section{Objectives}

The aim of this research is to study waiting time and its influencing factors, which helps to assess center's effectiveness after 9 years. We expect that this study may fill the current deficit in domestic literature about cardiac surgery waiting time and re-introduce it as an important measure for assessing the effectiveness of high technology purchasing and establishment at end-users' level.

\section{Patients and Methods}

This cross-sectional study performed in 2013 involved 156 patients referred to Amir Al-momenin Hospital of Kordkooy district, Kordkooy, Iran, for different kinds of heart surgeries. The patients were evaluated about demographic characteristics, accompanying disorders, economic status, education and type of surgery. Based on expert opinions (heart surgeons), heart performance index was the most important factor affecting our response variable (waiting time). Due to this opinion and using the New York Heart Association classification, which classifies heart performance in four classes, sample size was identified as 39 patients for each class (156 patients), which formed the study patients groups. Our four patient groups were as follows: The first group comprises patients whose activity is not compromised anyway. In contrast to this, the fourth one cannot do any activity without trouble (12). Participants were selected from patients who were nominated by heart surgeons for elective surgery. Because waiting time does not apply to urgent patients, they were excluded from study. All of the 156 cases were selected from patients spending recovery period in open-heart intensive care unit (ICU). Both checklist and observation were used as research tools. At first, researchers referred to patient medical records. They took notes about the date of admission, place of residence, date of referral from surgeon, accompanying diseases, impression, preoperative heart performance etc. Afterwards, more information about economic status, occupation, and other demographic data were collected through interviews with patients or relatives. Data about heart performance or left main coronary artery disease were derived by observing results of coronary angiographies and consultation with the physician.

Before any action, patient satisfaction to join in the study and attendance of researchers to their medical records were required. Participants usually report their economic status unreal. Therefore, we constructed a variable based on patient's annual income and asset scales, such as having personal automobile, computer, washing machine, and similar devices. For income scoring, living conditions were valued by two-thirds of asset score and one-third of income score. Based on this scoring we had:

- Poor group: monthly income $<167$ USD or $5000000 \mathrm{Ri}$ als (Iran currency) and having two assets (question number 10 of checklist-maximum score of 10).

- Good group: monthly income $\geq 334$ USD plus four points or more assets-minimum score 21.

- Moderate economic condition: scores from 10.1 to 21.

In data analysis, Kolmogorov-Smirnov and Shapiro tests were conducted first, to determine the normality of data. Because waiting time, as the main variable, was not normal in any subgroups, non-parametric tests like ManWhitney and Kruskal-Wallis substituted parametric tests, like the t test and ANOVA. Quantitative variables, described by Average and Standard Deviation were reported through presenting P value, by using Mean Rank report. For ethical consideration, interviews with patients and relatives and accessing patients' profile details have been done with patients' permission and hospital coordination.

\section{Results}

Of the 156 participants, $63.5 \%$ were male and $36.5 \%$ female. Inhabitants of urban areas were $69.8 \%$ and while 
$30.2 \%$ lived in rural areas. In terms of marital status, $1.9 \%$ were single, $94.9 \%$ married, $0.6 \%$ divorced and $2.6 \%$ widows or widowed men. There are different ethnicities in Golestan province. Therefore, it was predictable that our sample would be composed of different ethnicities. In this sense, we had $82.7 \%$ Persian or Fars (as an ethnicity), $6.4 \%$ Turkmen (a large minority who have formed, with Fars ethnicity, the indigenous population of Golestan province), 10.3\% Sistani (other minority who emigrated from southeast of Iran to the North) and 0.6\% others, which are composed of Baluch, Cossacks and Turks. The literacy rate was also calculated in our study, revealing 36.5\% illiterate, $27.6 \%$ at elementary or Literacy Movement Organization (a governmental agency which was established by decree of the Islamic republic of Iran, in 1980, to teach reading and writing to adults and children who are deprived of education), 13.5\% junior high school, $14.7 \%$ high school diploma, 0.6\% associate degree and 7.1\% bachelor or more (Table 1$)$.

Regarding to occupational level, $4 \%$ were unemployed, $5.8 \%$ government employee, $4.5 \%$ full-time self-employed (5-day in a week, 8 hours a day), 26.6\% part-time selfemployed, $25.3 \%$ housekeeper, $26 \%$ retired or disabled and $3.2 \%$ were farmer (Table 2 ). Review of patients medi- cal records revealed that, in terms of preoperative heart performance index, $19.1 \%$ were class I, $44.7 \%$ class II, $27 \%$ class III and 9.2\% class IV. Out of the respondents, $20 \%$ had left main coronary artery involvement versus $21.2 \%$ left main equivalent disease. Provision of surgical equipment (13.5\%), specialist absence (12.8\%), equipment failure (0.6\%), financial problems (28.2\%), personal problems (18.6\%), patient's health condition (1.3\%), specialist recommendation (12.8\%), specific drug consumption (3.8\%), hospital admission delay (1.9\%) were the most important causes of delay in surgical procedure. In $2.6 \%$ of cases, other factors were referred.

Among all participants, $87.2 \%$ had coronary artery bypass grafting (CABG), $6.4 \%$ heart valve surgery, $4.5 \%$ both of the previous surgeries and $1.9 \%$ other kind of heart surgery (Table 3). Concerning to outcome of surgery, most patients had complete remission (89.1\%), while several had partial remission (20\%) and fewer died (0.6\%). The current survey showed that $21.1 \%$ of participants had poor, $50.3 \%$ moderate and $28.6 \%$ good economic condition. There was no significant relation between waiting time and marriage status $(\mathrm{P}=0.85$ and mean rank was 93.33, 78, 56, 50, 72.25 for singles, married, divorced and widows respectively).

Table 1. The Relationship Between Waiting Times and Education Level of Patients Undergoing Cardiac Surgery

\begin{tabular}{lcccccc}
\hline Title & Number of Subjects & Average & Min & Max & SD & PValue \\
\hline Illiterate & 57 & 22.87 & 2 & 198 & 28.12 & 0.146 \\
Elementary & 43 & 19.81 & 3 & 158 & 29.54 & 0.146 \\
Junior High School Diploma & 23 & 23.57 & 1 & 209 & 47.11 & 0.146 \\
HS Diploma & 21 & 33.13 & 2 & 253 & 53.42 & 0.146 \\
Associate Degree & 1 & 6 & 6 & 6 & 0 & 0.146 \\
Bachelor and more & 11 & 10.81 & 3 & 21 & 7.57 & 0.146 \\
\hline
\end{tabular}

Table 2. The Relationship Between Waiting Time and Patients' Occupation

\begin{tabular}{lcccccc}
\hline Job status & Number of Subjects & Average & Min & Max & SD & PValue \\
\hline Unemployed & 13 & 22.38 & 5 & 55 & 18.64 & 0.201 \\
Government employee & 9 & 12.33 & 2 & 42 & 11.89 & 0.201 \\
\hline Self-employed full time & 7 & 37.57 & 4 & 198 & 71.11 & 0.201 \\
\hline Self-employed part time & 41 & 14.39 & 1 & 99 & 16.78 & 0.201 \\
Housekeeper & 39 & 29.74 & 2 & 209 & 42.57 & 0.201 \\
Retired & 40 & 24.40 & 3 & 253 & 41.76 & 0.201 \\
\hline Agriculture & 5 & 20.60 & 5 & 61 & 22.90 & 0.201 \\
\hline
\end{tabular}

Table 3. The Relationship Between Waiting Time and Type of Surgery

\begin{tabular}{lcccccc}
\hline Types & Number of Subjects & Average & Min & Max & SD & P Value \\
\hline CABG $^{\text {a }}$ & 136 & 21.70 & 1 & 253 & 33.07 & 0.657 \\
Valve replacement & 10 & 34.60 & 8 & 209 & 61.61 & 0.657 \\
Both & 7 & 30.14 & 4 & 109 & 38.96 & 0.657 \\
Others & 3 & 10.66 & 6 & 20 & 8.08 & 0.657 \\
\hline
\end{tabular}

\footnotetext{
${ }^{\mathrm{a}} \mathrm{CABG}$, coronary artery bypass graft.
} 
Badakhshan A et al.

Table 4. The Relationship Between Waiting Time and Patients' Economic Condition

\begin{tabular}{lcccccc}
\hline Title & Number of Subjects & Average & Min & Max & SD & P Value \\
\hline Week & 31 & 26.51 & 3 & 198 & 35.6 & 0.037 \\
Moderate & 74 & 20.52 & 2 & 209 & 26.74 & 0.037 \\
Good & 42 & 23.04 & 1 & 253 & 47.86 & 0.037 \\
Total & 147 & 22.51 & 1 & 253 & 35.59 & 0.037 \\
\hline
\end{tabular}

Table 5. The Relationship Between Waiting Time and Type of Disease

\begin{tabular}{lcccccc}
\hline Disease & No. $(\%)$ & Average & Min & Max & SD & P Value \\
\hline Left Main disease & & & & & 0.81 \\
$\quad$ Positive & $31(20)$ & 18.29 & 1 & 99 & 19.50 & \\
$\quad$ Negative & $124(80)$ & 23.62 & 2 & 253 & 38.35 & 0.34 \\
Left Main equivalent & & & & & 11.11 \\
$\quad$ Positive & $33(21.15)$ & 14.36 & 1 & 42 & 39.10 \\
$\quad$ Negative & $123(78.84)$ & 24.91 & 2 & 253 & \\
\hline
\end{tabular}

Table 6. The Relationship Between Waiting Time and Presence of Diabetes Mellitus

\begin{tabular}{lcccccc}
\hline Presence & Number of Subjects & Average & Min & Max & SD & P Value \\
\hline Positive & 78 & 20.51 & 1 & 185 & 24.18 & 0.265 \\
Negative & 78 & 24.84 & 2 & 253 & 43.79 & 0.265 \\
Total & 156 & 22.67 & 1 & 253 & 35.32 & 0.265 \\
\hline
\end{tabular}

Table 7. The Relationship Between Waiting Time and Preoperational Heart Performance Grade

\begin{tabular}{lcccccc}
\hline Grades & No. $(\%)$ & Average & Min & Max & SD & P Value \\
\hline $\mathbf{1}$ & $29(19.07)$ & 24.96 & 4 & 37.83 & 37.83 & 0.749 \\
$\mathbf{2}$ & $68(44.73)$ & 24.04 & 1 & 198 & 36.20 & 0.749 \\
$\mathbf{3}$ & $41(26.97)$ & 14.51 & 3 & 42 & 10 & 0.749 \\
$\mathbf{4}$ & $14(9.21)$ & 34.78 & 3 & 253 & 64.69 & 0.749 \\
\hline
\end{tabular}

There was no significant relation between waiting time and gender $(\mathrm{P}=0.371)$. Based on the findings (Table 4$)$, waiting time was significantly influenced by economic status, as Kruskal-Wallis test shows $(\mathrm{P}=0.037)$.

There was no significance between waiting time and ethnicity, place of residence and religion ( $P$ value was $0.664,0.08$ and 0.429 , respectively). Findings of relationship between waiting time and type of surgery, type of disease, accompanying disease, and preoperative heart performance are shown in Tables 3 and 5 - 7 .

There was no relation between waiting time and presence of hypertension (HTN) and history of myocardial infarction $(\mathrm{P}=0.983$ and 0.274 , respectively).

\section{Discussion}

The current study shows no relation between waiting time and demographic characteristics, while many investigations around the world have revealed this fact. A study conducted by Ray and his colleagues reveals that long waiting time in women is due to more sensitivity they have about their health and not because of gender. This sensation drives them to be obsessive and follow more for consultation. Therefore, their health problem is discovered in early stages and enough time is spent to prepare for the surgical intervention. In a study conducted by Ray et al. (13), P values were 0.518 and 0.481 for men and women, respectively, in comparison with ours, which was 0.371 .

Arnesen et al. (14) assumed that waiting time and gender have no association with each other. Their conclusion is similar to our research. Naylor et al. (15), in their study titled "queuing for coronary surgery" also concluded the same. According to the study by Arnesen et al. (14), age group $\geq 70$ years had the shortest waiting time among other age groups. In the current study, this age group had longer waiting time than the age group $<70$ (28.6 versus 21.5 days, respectively, $\mathrm{P}=0.068$ ).

Ray et al. (13) showed that surgery outcome is affected by several risk factors, such as history of heart surgery and myocardial infarction, and there was no relation with waiting time. 
Ajami and Ketabi (16), studied bottlenecks in the discharge process, concluded that patient's financial problem influences waiting time, as an important factor. Alter et al. (17) studied the effects of socioeconomic status on access to invasive cardiac procedures. They concluded that increased neighborhood income associates with shorter CABG waiting time. Pell et al. (18) concluded that socioeconomically deprived patients, besides their worse medical condition and less access to investigations, are further disadvantaged, because should wait longer for surgery because of lower priority. The current study revealed that the economic status has considerable impact on waiting time. This means that a weaker economic condition is associated with longer waiting list. Kee et al. (19) found no significant relation between occupational condition and waiting time, which is consistent with our study $(\mathrm{P}=0.201)$.

Naylor et al. (15) concluded that there is an inverse relation between patient's neighborhood income quartile and waiting time. The current study, similarly to previous studies about economic status, is exposed to the risk of under reporting the financial status of the participants. This is especially due to costly services of heart surgery and fear of failure to commute. Therefore, using a combined variable, formed from patients self-reporting, and having living facilities reduce this concern. Hurst and Sisiliani (20), in their article, titled tackling excessive waiting times for elective surgery in 12 OECD countries, reported that average waiting time is about 3 months, which could be increased to 1 year. In Denmark, prolonged waiting time for CABG surgeries was reduced permanently through increasing practices and supporting capacity buildings (20).

Hurst and Sisiliani (20) also reported that the proportion of studied people who waited for more than 12 weeks for surgery was 58.1\% in Portugal, $41.7 \%$ in Switzerland and $36.3 \%$ in Italy. Other findings of similar studies have revealed 28\% in Norway, $19.4 \%$ in Germany, $18.5 \%$ in Spain, 16.1\% Switzerland, 15.2\% Netherlands and 13.3\% Hungary (20). Waiting time average was about 30 days in England, in 1991, which increased to about 190 days, in 2001(21).

One of the proposed solutions for decreasing the need to elective surgeries is the substitution of public financing by private methods. When the public services are in poor condition, or private services are strong and choosing of the providers could be done by patients, this is useful. We should consider that increasing private insurance coverage can cause more demand and give the opposite result.

Private insurance coverage can give the patient a shift from public services to private sector. However, this decrease in waiting time can come at the cost of undermining incentives to buy voluntary private insurance. In fact, waiting lists with other factors such as income, age and political preferences have a major role in inducing private insurance purchasing. On the other hand, a patient who has been confronted with paying increased co- payment may choose to return to the public insurance. Finally, if the private sector confronts with limiting marketing legislation or staff shortage, accessing to shorter waiting lists may be postponed. Based on our research, patients with just basic insurance had no difference regarding waiting time compared with more expensively insured patients.

Arnesen et al. (14) considered socioeconomic characteristics as important waiting time influencing factors and especially focused on urology, gynecology and orthopedic elective surgeries. They estimated waiting time between 6 and 846 days (61, as average). In their study, patients with malignancy or serious complications had shorter waiting time and the factors affecting waiting time are patient's conditions, physician's situation and type of disease.

Our research did not found a significant relation between waiting time and disease type. In other words, patients with left main coronary artery involvement had an average waiting time of about 18.2 days, whereas for patients without the aforementioned involvement it was 23.6 days. $(P=0.128)$.

In Naylor et al. research (15), symptoms and anatomy of lesion were the most important waiting time determinants. Ray et al. (13) showed that most patients (86\%) had diabetes mellitus (DM), involvement of three vessels, stenosis of left main or both vessels.

We found that $50 \%$ of our participants had DM (Table 5) and $20 \%$ stenosis of left main artery. There was no association between waiting time for patients' who just had DM (22.3 days) and patients with both DM and hypertension (21.7 days, $\mathrm{P}=0.662$ ).

No comparison was found between different ethnic group waiting times, in literature review. As mentioned earlier, although Golestan province population is composed of various ethnic groups, our research did not show any significant difference between waiting time of ethnic groups $(\mathrm{P}=0.82)$.

Patients usually do not talk about asking extra-payment by physician or referring them to private sector, for more charge. They fear it may have an adverse impact on their treatment. Although the reality pointed above is a limitation of our study, several general statements, such as financial problem or specialist recommendation, as the first and third factors influencing waiting time, reflect this concern.

\subsection{Recommendations}

Launching heart surgery wards has always been one of politicians' favorites, whether they are directly related to the health sector or not. Patients who decide to undergo surgery, on one hand, are worried that their decision will not necessarily lead to cure or even result in death. On the other hand, they are worried that their intention may impose catastrophic costs.

Therefore, it is acceptable that the proximity of heart 
surgery wards to people's accommodation can be an important factor for establishment. This strategy, in addition to diminishing waiting time, can reduce insensible costs, such as commuting costs.

This study suggests that the heart center under study has acceptable waiting times. It should be noted that, due to the lack of specific studies for the waiting time for elective cardiac surgery, its standard are selected according to the researcher's opinion. Because of that, our study fairly has inherent weaknesses. Therefore, we recommend that other studies about heart surgery waiting time should consider different types of heart diseases.

Except the economic condition, other variables had no significant relation with waiting time. This suggests that the studied heart center, regardless of gender, settlement, education and occupation, considers fairness in determining waiting time. However, if waiting time for several conditions is considered, this should make managers aware of falling into other kinds of unfairness or in better expression, mismanagement. For example, we found that women in all age groups had longer waiting time compared to men. By opinion of Ray et al. (13) this translates that women are more sensitive to their health, although the difference probably has other points that should be considered.

Although more attention should be given to patients over 70 years, the waiting list in this group is longer than young people. Consulting with specialists did not show any cost-effective analysis regarding QALY league tables, to justify this difference.

Surprisingly, patients with poor heart condition deserve to undergo surgery earlier, even if our study shows no significant association. Currently, specialist opinion is the third factor in waiting time determination (12.8\%). It seems that managers should review their waiting time standards and change them to more important determinants. Based on study of Seddon et al. (22), in New Zealand, today we witness a move to more explicit decisions. As noted, patient's economic condition is the only variable which significantly associates with waiting time. On the other hand, financial and personal problems are also important factors that cause waiting time elongation (28.2 and $18.6 \%$, respectively). These facts highlight the role of the ministry of health, insurance and other supporting organizations in protecting privileged groups.

Increasing health insurance makes the load of hospital costs and physician's informal payments more bearable. In addition to increasing health insurance coverage, waiting time for heart surgery can be further reduced by providing the cost of surgery. Implementing strategies, like in the for costs of patients injured in road accidents, could satisfy both patients and providers (23).

Personal problems are reported by patients as the second cause of waiting time elongation. It seems that most of it is due to fear and suspicion about outcomes. Considering psychological consultation and introducing technical and professional abilities, besides provid- ing comfortable atmosphere, could be definitely useful. Tabibi et al. (24) recommended that training the providers and supporting managers could be effective. Freeman and Denham (25) suggest three important principles for nurses to cope with the anxiety of patients and their relatives. First, the value of patients' time should be appreciated by nurses. Second, clear communication at the admission about the expected surgical time and potential problems that might lead to delays. Third, empowerment or use of a contract that establishes the nurses' intent to see the patient goes to surgery at the scheduled time (25). Pitrou et al. (26) stressed that long waiting time is considered an independent and exclusive risk factor for patients' dissatisfaction. They recommend that giving information about delay and its causes act as a right strategy in patient satisfaction.

This study has several limitations. As noted earlier, reporting the economic condition by the patient is not reliable. Because of that, we used a summary measure composed of reported income and living amenities. Another limitation is concerns the standard of heart surgery waiting time, that is derived subjectively from expert opinions.

Participatory management, with application of total quality management principles, could improve waiting time. In consistence with Mossadegh-Rad (27) opinion, it could be appropriate if the area of participative management, such as staff training, creating culture of participation by directors and employees, proper incentives and commitment of senior management is available. Soremekun et al. (28) have addressed this issue from another perspective. They believe that correcting patients' perception about waiting time, through improving patient-physician interactions, greater understanding of patients about their care, and improving their waiting experience, are key elements in promoting patients satisfaction.

Finally, we should not be unaware about the role of DM in heart surgery success rate. As noted, DM was comorbidity in $50 \%$ of our participants. This statistics is frankly different from other studies (23\%). This finding underlines that we should, as soon as possible, determine the role of DM or controlling it in the prognosis of heart surgery.

It is important that not all the diabetic patients mentioned previous history of myocardial infarction. Therefore, the fact that DM directly affect the prognosis, regardless of its role in predisposing to atherosclerosis, could be considered by clinical researchers (29). Lemp et al. (30) assumed that the risk of coronary artery disease increases with the severity, rather than duration of diabetes mellitus. For a given level of severity of DM, the risk of CAD did not differ by anatomic location, within the coronary tree.

\section{Acknowledgements}

The research department of Tehran University of Medical Sciences, Tehran, Iran, funded and approved this 
study, by contract issued number 17310 in 16 April 2013. The authors are grateful to all those who provided advice and assistance in this research. We also appreciate Dean of Kordkooy Amir Al-momenin Hospital, Dr. Emami and heart ICU personnel, especially Mrs. Amtaeh and Mr. Yazdani.

\section{Authors' Contributions}

Abbas Badakhshan and Mohammad Arab were involved, as key researchers, in study design, coordination and data gathering. Mahin Gholipour in date gathering and interviews. Naser Behnampour helped for statistical analysis and Saeid Saleki was involved as technical consultant.

\section{Funding/Support}

The research is supported by Tehran University of Medical Sciences, Tehran, IR Iran, Deputy of Research and International Campus.

\section{References}

1. Sharples LD, Caine N, Mullins P, Scott JP, Solis E, English TA, et al Risk factor analysis for the major hazards following heart transplantation--rejection, infection, and coronary occlusive disease. Transplantation. 1991;52(2):244-52.

2. Bar-dayan Y, Leiba A, Weiss Y, Carroll JS, Benedek P. Waiting time is a major predictor of patient satisfaction in a primary military clinic. Mil Med. 2002;167(10):842-5

3. van Harten MC, Hoebers FJ, Kross KW, van Werkhoven ED, van den Brekel MW, van Dijk BA. Determinants of treatment waiting times for head and neck cancer in the Netherlands and their relation to survival. Oral Oncol. 2015;51(3):272-8.

4. Golaghaie F, Sarmadian H, Rafiie M, Nejat N. A study on waiting time and length of stay of attendants to emergency department of Vali-e-Asr Hospital, Arak-Iran. Arak Med Uni J. 2008;11(2):74-83.

5. Tabibi SJ, Shoaie S. Waiting time in the emergency department in selected hospitals of Iran University of Medical Sciences in 2007. Pejouhesh. 2009;33(2):117-22.

6. Siciliani L, Stanciole A, Jacobs R. Do waiting times reduce hospital costs? J Health Econ. 2009;28(4):771-80.

7. Keijzers G, Crilly J, Walters B, Crawford R, Bell C. Does a dedicated pediatric team within a busy mixed emergency department make a difference in waiting times, satisfaction, and care transition? Pediatr Emerg Care. 2010;26(4):274-80.

8. Anderson RT, Camacho FT, Balkrishnan R. Willing to wait?: the influence of patient wait time on satisfaction with primary care. BMC Health Serv Res. 2007;7:31.

9. Solans-Domenech M, Adam P, Tebe C, Espallargues M. Developing a universal tool for the prioritization of patients waiting for elective surgery. Health Policy. 2013;113(1-2):118-26

10. Naylor CD, Levinton CM, Baigrie RS. Adapting to waiting lists for coronary revascularization. Do Canadian specialists agree on which patients come first? Chest. 1992;101(3):715-22.
11. Eisenberg JM. Sociologic influences on decision-making by clinicians. Ann Intern Med. 1979;90(6):957-64.

12. Holland R, Rechel B, Stepien K, Harvey I, Brooksby I. Patients' selfassessed functional status in heart failure by New York Heart Association class: a prognostic predictor of hospitalizations, quality of life and death. J Card Fail. 2010;16(2):150-6.

13. Ray AA, Buth KJ, Sullivan JA, Johnstone DE, Hirsch GM. Waiting for cardiac surgery: results of a risk-stratified queuing process. Circulation. 2001;104(12 Suppl 1):I92-8.

14. Arnesen KE, Erikssen J, Stavem K. Gender and socioeconomic status as determinants of waiting time for inpatient surgery in a system with implicit queue management. Health Policy. 2002;62(3):329-41.

15. Naylor CD, Levinton CM, Wheeler S, Hunter L. Queueing for coronary surgery during severe supply-demand mismatch in a Canadian referral centre: a case study of implicit rationing. Soc Sci Med.1993;37(1):61-7.

16. Ajami S, Ketabi. S. Bottlenecks on discharge process in Beheshti Hospital. Health Inf Manag J. 2008;5(5):35-43.

17. Alter DA, Naylor CD, Austin P, Tu JV. Effects of socioeconomic status on access to invasive cardiac procedures and on mortality after acute myocardial infarction. NEngl J Med.1999;341(18):135967.

18. Pell JP, Pell AC, Norrie J, Ford I, Cobbe SM. Effect of socioeconomic deprivation on waiting time for cardiac surgery: retrospective cohort study. BMJ. 2000;320(7226):15-8.

19. Kee F, McDonald P, Gaffney B. Prioritising the cardiac surgery waiting list: the angina patient's perspective. Heart. 1997;77(4):330-2.

20. Hurst J, Sisiliani L. Tackling Excessive Waiting Times for Elective Surgery. OECD Health Working Paper. 2003;6.

21. Blendon RJ, Schoen C, DesRoches CM, Osborn R, Scoles KL, Zapert K. Inequities in health care: a five-country survey. Health Aff (Millwood). 2002;21(3):182-91.

22. Seddon ME, French JK, Amos DJ, Ramanathan K, McLaughlin SC, White HD. Waiting times and prioritization for coronary artery bypass surgery in New Zealand. Heart. 1999;81(6):586-92.

23. Sharif-Zare M. Surveying the satisfaction of victims and officials from executing instruction article 92 in the health centers. Isfahan Uni of Med Sci Homaye salamat. 2011;40:32-5.

24. Tabibi SJ, Najafi B, Shoaie S. Waiting time in the emergency department in selected hospitals of Iran University of Medical Sciences in 2007. Pejouhesh. 2009;33(2):117-22.

25. Freeman K, Denham SA. Improving patient satisfaction by addressing same day surgery wait times. J Perianesth Nurs. 2008;23(6):387-93.

26. Pitrou I, Lecourt AC, Bailly L, Brousse B, Dauchet L, Ladner J. Waiting time and assessment of patient satisfaction in a large reference emergency department: a prospective cohort study, France. EurJ Emerg Med. 2009;16(4):177-82.

27. Mossadegh-rad AM. Participatory management role in hospital efficiency and effectiveness. J Res Med Sci. 2003;3:85.

28. Soremekun OA, Takayesu JK, Bohan SJ. Framework for analyzing wait times and other factors that impact patient satisfaction in the emergency department. J Emerg Med. 2011;41(6):686-92.

29. Flaherty JD, Davidson CJ. Diabetes and coronary revascularization. JAMA. 2005;293(12):1501-8.

30. Lemp GF, Vander Zwaag R, Hughes JP, Maddock V, Kroetz F, Ramanathan KB, et al. Association between the severity of diabetes mellitus and coronary arterial atherosclerosis. Am J Cardiol. 1987;60(13):1015-9. 